Network Working Group

Request for Comments: 5131

Category: Standards Track
D. McWalter, Ed. Data Connection Ltd December 2007

\title{
A MIB Textual Convention for Language Tags
}

Status of This Memo

This document specifies an Internet standards track protocol for the Internet community, and requests discussion and suggestions for improvements. Please refer to the current edition of the "Internet Official Protocol Standards" (STD 1) for the standardization state and status of this protocol. Distribution of this memo is unlimited.

Abstract

This MIB module defines a textual convention to represent BCP 47 language tags. The intent is that this textual convention will be imported and used in MIB modules that would otherwise define their own representation.

Table of Contents

1. Introduction . . . . . . . . . . . . . . . . . . . . . 2

2. Terminology . . . . . . . . . . . . . . . . . . . . . . . . . . 2

3. The Internet-Standard Management Framework . . . . . . . . . . 2

4. Definitions . . . . . . . . . . . . . . . . . . . . . . 3

5. Security Considerations . . . . . . . . . . . . . . . . . 4

6. IANA Considerations . . . . . . . . . . . . . . . . . . . . 4

7. Acknowledgements . • . . . . . . . . . . . . . . . . . . 4

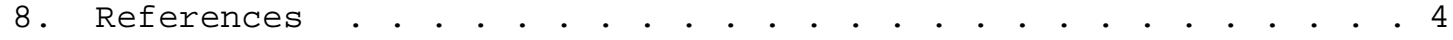
8.1. Normative References . . . . . . . . . . . . . . . . . . 4 8.2. Informative References . . . . . . . . . . . . . . . . 5 


\section{Introduction}

This memo defines a portion of the Management Information Base (MIB) for use with network management protocols in the Internet community. It defines a textual convention to represent BCP 47 [RFC4646] language tags.

The LangTag TEXTUAL-CONVENTION defined by this RFC replaces the similar LanguageTag TEXTUAL-CONVENTION defined by RFC 2932 [RFC2932].

The old LanguageTag TEXTUAL-CONVENTION is used by some existing MIB modules. New MIB modules should use the LangTag TEXTUAL-CONVENTION, which has been created (and is to be preferred) for the following reasons:

- Its syntax description is current, and is more comprehensive.

- It is short enough to use as an index object without subtyping, yet is of adequate length to represent any language tag in practice.

- It is provided in a dedicated MIB module to simplify module dependencies.

It is not possible to apply changes in syntax and length to an existing textual convention. This is why the creation of a new textual convention with a new name was necessary.

2. Terminology

The key words "MUST", "MUST NOT", "REQUIRED", "SHALL", "SHALL NOT", "SHOULD", "SHOULD NOT", "RECOMMENDED", "MAY", and "OPTIONAL" in this document are to be interpreted as described in RFC 2119 [RFC2119].

3. The Internet-Standard Management Framework

For a detailed overview of the documents that describe the current Internet-Standard Management Framework, please refer to section 7 of RFC 3410 [RFC3410].

Managed objects are accessed via a virtual information store, termed the Management Information Base or MIB. MIB objects are generally accessed through the Simple Network Management Protocol (SNMP). Objects in the MIB are defined using the mechanisms defined in the Structure of Management Information (SMI). This memo specifies a MIB module that is compliant to the SMIV2, which is described in STD 58, RFC 2578 [RFC2578], STD 58, RFC 2579 [RFC2579] and STD 58, RFC 2580 [RFC2580]. 
4. Definitions

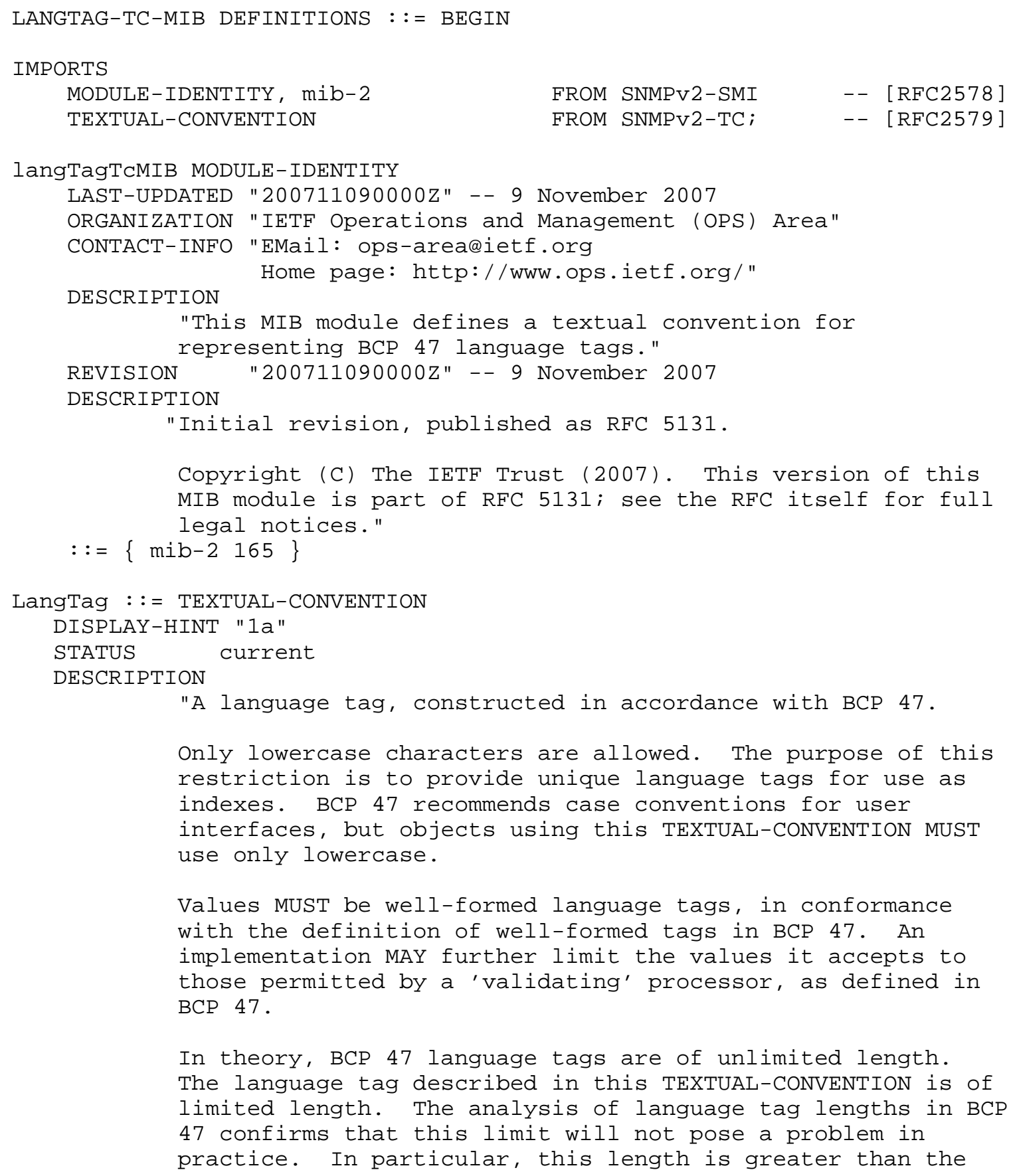




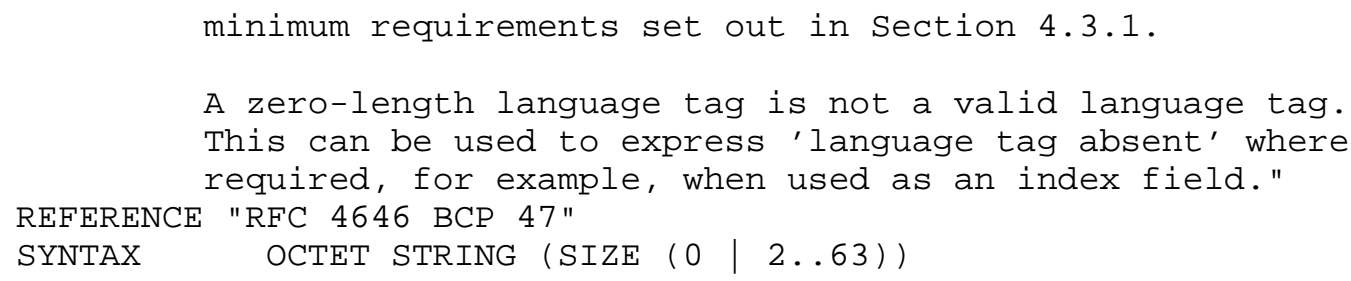

END

5. Security Considerations

This MIB module does not define any management objects. Instead, it defines a textual convention that may be imported by other MIB modules and used for object definitions.

Meaningful security considerations can only be written in the MIB modules that define management objects. This document therefore has no impact on the security of the Internet.

6. IANA Considerations

LANGTAG-TC-MIB is rooted under the mib-2 subtree. IANA has assigned $\{$ mib-2 165$\}$ to the LANGTAG-TC-MIB module specified in this document.

7. Acknowledgements

This MIB module is a reworking of existing material from RFC 2932.

This module was generated by editing together contributions from Randy Presuhn, Dan Romascanu, Bill Fenner, Juergen Schoenwaelder, Bert Wijnen, Doug Ewell, and Ira McDonald.

8. References

8.1. Normative References

[RFC2119] Bradner, S., "Key words for use in RFCs to Indicate Requirement Levels", BCP 14, RFC 2119, March 1997.

[RFC2578] MCCloghrie, K., Ed., Perkins, D., Ed., and J. Schoenwaelder, Ed., "Structure of Management Information Version 2 (SMIv2)", STD 58, RFC 2578, April 1999.

[RFC2579] McCloghrie, K., Ed., Perkins, D., Ed., and J. Schoenwaelder, Ed., "Textual Conventions for SMIv2", STD 58, RFC 2579, April 1999. 
[RFC2580] McCloghrie, K., Perkins, D., and J. Schoenwaelder, "Conformance Statements for SMIV2", STD 58, RFC 2580, April 1999.

[RFC4646] Phillips, A. and M. Davis, "Tags for Identifying Languages", BCP 47, RFC 4646, September 2006.

8.2. Informative References

[RFC2932] McCloghrie, K., Farinacci, D., and D. Thaler, "IPv4 Multicast Routing MIB", RFC 2932, October 2000.

[RFC3410] Case, J., Mundy, R., Partain, D., and B. Stewart, "Introduction and Applicability Statements for InternetStandard Management Framework", RFC 3410, December 2002.

Author's Address

David McWalter (editor)

Data Connection Ltd

100 Church Street

Enfield EN2 6BQ

United Kingdom

EMail: dmcw@dataconnection.com 
Full Copyright statement

Copyright (C) The IETF Trust (2007).

This document is subject to the rights, licenses and restrictions contained in BCP 78, and except as set forth therein, the authors retain all their rights.

This document and the information contained herein are provided on an "AS IS" basis and THE CONTRIBUTOR, THE ORGANIZATION HE/SHE REPRESENTS OR IS SPONSORED BY (IF ANY), THE INTERNET SOCIETY, THE IETF TRUST AND THE INTERNET ENGINEERING TASK FORCE DISCLAIM ALL WARRANTIES, EXPRESS OR IMPLIED, INCLUDING BUT NOT LIMITED TO ANY WARRANTY THAT THE USE OF THE INFORMATION HEREIN WILL NOT INFRINGE ANY RIGHTS OR ANY IMPLIED WARRANTIES OF MERCHANTABILITY OR FITNESS FOR A PARTICULAR PURPOSE.

Intellectual Property

The IETF takes no position regarding the validity or scope of any Intellectual Property Rights or other rights that might be claimed to pertain to the implementation or use of the technology described in this document or the extent to which any license under such rights might or might not be available; nor does it represent that it has made any independent effort to identify any such rights. Information on the procedures with respect to rights in RFC documents can be found in BCP 78 and BCP 79 .

Copies of IPR disclosures made to the IETF Secretariat and any assurances of licenses to be made available, or the result of an attempt made to obtain a general license or permission for the use of such proprietary rights by implementers or users of this specification can be obtained from the IETF on-line IPR repository at http://www.ietf.org/ipr.

The IETF invites any interested party to bring to its attention any copyrights, patents or patent applications, or other proprietary rights that may cover technology that may be required to implement this standard. Please address the information to the IETF at ietf-ipreietf.org. 